\title{
How Prospective Teachers Conceptualized Mathematics: Implications for Teaching
}

\author{
Eric Fredua-Kwarteng \\ Ontario Institute for Studies in Education, CANADA \\ •Received 12 November 2014•Revised 16 May 2015•Accepted 29 July 2015
}

\begin{abstract}
What is mathematics? The difficulty of having a precise, universal definition of mathematics has led prospective teachers to define the term in ways that make sense to them. This paper is part of a larger research project conducted in 2000 in an Ontarian university, Canada. The objectives were to identify and discuss conceptualizations of mathematics that prospective teachers brought to their preparation program and to explore the implications of such conceptualizations in terms of teaching and learning. It was believed that both the identification tools and understandings of prospective teachers' conceptualizations of mathematics were significant for designing an effective pedagogy in accordance with mathematics reform-based perspectives. The research sample consisted of ten prospective teachers enrolled in a one-year bachelor of education program at an Ontarian university. The research used mathematics autobiographies of the respondents and semi-structured interviews of them as sources of data. Guided by the theory of personal construct for analysis of the data, the results showed that the respondents conceptualized mathematics in terms of metaphor, metonymy and combination of the two. The conclusion explores implications of such conceptualizations for mathematics teaching, learning and assessment.
\end{abstract}

Keywords: conceptions of mathematics, language, metaphoric, metonymic, pre-service teachers, teachers' math autobiographies

\section{INTRODUCTION AND PURPOSE OF RESEARCH}

Over the years, mathematics educators, researchers and theorists have used different strategies to think about the nature of mathematics. Philosophically, two dominant schools of thought can be associated with the nature of mathematics: Absolutism and fallibilism (Ernest, 1996). The absolutist orientation views mathematics as objective, absolute, and incorrigible body of knowledge that has been discovered and built on foundations of deductive logic. The fallibilist philosophy, on the other hand, views mathematics as a social construction, fallible and open to revision and interpretation in respect of its proofs and concepts.

These philosophical orientations tend to influence mathematics teaching and learning; yet teacher educators in Ontarian universities hardly provide opportunities for prospective teachers to explore their conceptualizations of mathematics and their ramifications on teaching and learning of mathematics. While

Correspondence: Eric Fredua-Kwarteng,

Ontario Institute for Studies in Education, 252 Bloor Street, Sixth Floor, Toronto, Ontario, Canada.

E-mail: efredua_2000@yahoo.ca

doi: $10.29333 /$ iejme/293 
teacher education programs in Ontarian universities equip prospective teachers with pedagogical, curricular and assessment knowledge and skills, those prospective teachers' conceptualizations of the nature of mathematics remain a private matter. However, research has indicated that conceptualization of mathematics has effects on its teaching and learning. Dossey (1992) argued that conceptualizations of the nature of mathematics could influence the teaching of mathematics and eventually shape how children view mathematics and its role in the world. Similarly, Presmeg (2002) contended that conceptualizations about the nature of mathematics may be an enabling or hindering force for the "bridging process between every day practices and school mathematics" (p. 295).

About twenty-seven years ago, Ball (1988) stated that prospective teachers always bring to their professional preparation program preconceived knowledge of what mathematics is about, how to teach and learn it. Ball (1991) further listed the following conceptualizations of mathematics that prospective teachers bring into their preparation:

- Doing mathematics means following a set of procedures step-by-step to arrive at answers.

- Knowing mathematics means knowing "how to do it."

- Mathematics is largely an arbitrary collection of facts and rules.

- A primary reason to learn mathematics is to progress to the next level in school.

- Another main purpose for learning math is to be able to calculate prices at the store.

- Most mathematical ideas have little or no relationship to real objects and therefore canbe represented only symbolically (p. 18).

Part of the etiology of these conceptualizations of mathematics may be attributed to the complexity in deciphering its nature. As Ernest (2010) rightly acknowledged, mathematics is both complex and ambiguous. Its ambiguity lies, as Ernest (2010) stated, in the fact that it is a plural word yet treated as a singular entity. He also added that mathematics is complex in that "it is an organized body of knowledge, a practice engaged by mathematicians, a school subject, a cultural object of many meanings, and a language and box of conceptual tools used variously in many different practices" (p. 99).

Even official documents such as the Ontario mathematics curriculums (grades18. 9-10, 11-12) have avoided offering any definition of the nature of mathematics, unlike the current school mathematics curriculum in New Zealand that has attempted to define the nature of mathematics:

Mathematics makes use of specific language and skills to model, analyse, and interpret the world...[It] involves creativity and imagination in the discovery of patterns of shape and number, the perceiving of relationships, the making of models, the interpretation of data, and the communication of emerging ideas and concepts". ((New Zealand Ministry of Education, 1992, p. 7)

Instead, the Ontario mathematics curriculums outlined seven processes of mathematics learning: problem-solving, reasoning and proving, reflecting, selecting tools and computational strategies, connecting, representing and communicating (Ontario Ministry of Education, 2005b and 2007). These conceptualizations of mathematics, as we will later see, are indeed metonymic. The implicit assumption underlying these curriculum documents is that teachers understand the nature of mathematics to allow them to teach it effectively. Nonetheless, it will be difficult for prospective teachers to teach a discipline whose nature and objects are undefined and vague. 
The main purpose of this research was to identity prospective teachers' conceptualizations of the nature of mathematics and to explore the implications of those conceptualizations for teaching and learning. Prospective teachers' mathematics autobiographies and semi-structured interviews were the data collection instruments used to identify their conceptualizations of mathematics. The identification tools and understanding of prospective teachers' conceptualizations were deemed necessary for designing a pedagogy that provides ample opportunities to enable them to analyze the practical implications of their conceptualizations for mathematics teaching, learning and assessment. This paper is, thus, a contribution to the literature on pre-service teachers' knowledge and experience of mathematics they bring to teacher preparation, particularly the use of linguistic devices to makesense of the nature of mathematics.

According to Steele and Widman (1997) conceptualization is a construct consisting of two components: beliefs and knowledge. They referred to beliefs as personal views, assumptions, and values; and knowledge as the ability to choose tasks, problems, representations, and explanations that help students to learn mathematics. However, Leatham (2006) took conceptualization as a general category comprising a number of constructs such as beliefs, knowledge, understanding, preferences, meanings, and values. This broader view of conceptualization will be adopted in this paper, because conceptualization of mathematics could be more than beliefs and knowledge. It includes one's attitude toward mathematics, mental picture of mathematics, schools of thought, or perspectives of the nature of mathematics.

The paper is organized into five sections. The first section reviews briefly the literature on teacherconceptualizations of mathematics. The second section deals with the theoretical prism informingthe research. The third part describes the research settings, along with the data collection instruments used and methods of data analysis. The forth part reports and discusses the findings. The final section explores the probable implications of such conceptualizations of mathematics for teaching and learning of mathematics.

\section{LITERATURE REVIEW}

The use of personal construct theory to study the mathematics conceptualizations of practicing and prospective teachers is not a new phenomenon. McQualter (1986) used personal construct theory to examine common assumptions, beliefs or notions about mathematics teaching that prospective mathematics teachers bring to their teacher preparation program. McQualter (1986) found that prospective teachers are active constructors of mathematics and that to understand them one has to find out how they develop their repertoire of skills based on their personal knowledge and beliefs. Lehrer and Franke (1992) also used personal construct theory to study the content and organization of two teachers' knowledge of fractions. One of their findings is that a relationship exists between the teachers' constructs of fractions and their classroom teaching practice.

Thompson (1984) also studied mathematics conceptions of three practicing junior high school teachers using case study method with, interview, and classroom observations as sources of data. She found that the teachers' instructional behavior and practices were influenced significantly by their conceptions of mathematics. Thompson's (1984) work is more significant for planning professional development programs for in-service teachers rather than for pre-service teachers. As well, Steele and Widman (1997) studied five randomly selected female prospective teachers about their conceptualizations of mathematics after they had been taught mathematics based on the constructivist pedagogy embodied in the NCTM (National Council of Teachers of Mathematics) principles. They used participant observation, 
interviewing and collection of artifacts as their data collection methods. The study is based on four set of questions: What is mathematics? What does it mean to know mathematics? How is mathematics learned? How would you teach mathematics? The result was that those prospective teachers' changed their conceptualizations of mathematics due to the adoption of the constructivist pedagogy.

Zazkis and Campbell (1996) also studied pre-service teachers' conceptions of prime decomposition and concluded that the difficulty with this concept stemmed from previous experiences involved in expressing composite numbers as products. Again, Zazkis and Gunn (1997) studied pre-service teachers' conceptions or misconceptions of set theory-set cardinality, set elements, subset, and the empty set- after the topic had been taught. They suggested that the pre-service teachers had difficulties with that concept owing to their deep-rooted tendency to assign their own contrived meanings to those concepts.

Andrews and Hatch (1999) also surveyed 577 teachers of secondary school mathematics in the United Kingdom with the object of understanding their conceptions of the nature of mathematics and mathematics teaching. Using factor and correlation analysis, they concluded that the teachers conceived mathematics in five ways. First, mathematics was seen as a personal economic tool in that it assisted individuals to manage household expenses or budget. Second, the respondents looked at mathematics as a pleasurable activity; that is, people gain ecstatic pleasure from doing mathematics. Third, mathematics was conceived as an essential life-tool that allows people to understand the world around them and make informed decisions. Forth, mathematics was also conceived as a service provider to other sectors of human endeavour such as science, commerce $\backslash$ industry, and technology. In this respect mathematics is a collection of procedures for application, not necessarily to understand it. Finally, the teachers conceived that teachers are actually mathematics curriculum determiners, not the government.

In addition, Andrews and Hatch's (1999) research reveals five conceptions of mathematicsteaching. The respondents conceived mathematics teaching as both a process-oriented as well asskills-oriented. They also conceived that while mathematics learning is an individualized activity, it could also be a collaborative and co-operative act. Lastly, the result indicates that mathematics teachers have the responsibility to create a mathematically enriched classroom setting where student can learn. For McDuffie and Slavit (2003) online discussion of issues relating to teaching and learning of mathematics allowed students to share their reflections, thoughts, questions, and dilemmas freely than in a spoken face-to-face situation. The authors contended that this pedagogical approach enabled the instructors to design appropriate interventions and for the students to engage in more focused reflections of their conceptions of mathematics. Certainly, there are inherent problems in this approach, including access to reliable computer technology, time, and clarity of communication.

The problem of identifying and addressing pre-service teacher conceptualizations of mathematics has been a major challenge to researchers and scholars in the field of teacher education. Zazkis (1999) has stated that the basic problem in the mathematics education of pre-service teachers is how to challenge basic assumptions they bring to teacher education. Nevertheless, she went on to suggest that of greater significance is how to identify those assumptions before one can challenge them. She further suggested that interviewing prospective teachers about how they conceptualize mathematics is one such effective device. Timmerman's (2004) research also suggested that three intervention instruments consisting of problem-solving journals, structured interviews, and peer teaching are influential in changing pre-service teachers' conceptions about reform-oriented mathematics education goals. 
Furthermore, Noyes (2006) studied prospective teachers' conceptions of mathematics by using metaphors as a theoretical framework. He allowed the prospective teachers to reflect, discuss, and critique their mathematics metaphors with the object of challenging the originators of the metaphors. He acknowledged that while the study offers reflective and critical tools for pedagogy, the results show that there are pedagogical consequences of the various metaphors used to conceptualize mathematics.

Other researchers in the field have looked at the broader etiology of prospective teachers' conceptualizations of mathematics rather than being content with generic words like beliefs, values, assumptions or conceptions. Johanne (2006), for example, traced sources of pre-service teacher conceptions of mathematics to social experiences through school, peers, parents, and the mass media. Similarly, Gates (2006) traced beliefs about the nature of mathematics, mathematics teaching and learning to social experiences. He suggested that upbringing and socialization, personal and society ideology, and professional discourses as the constitutive sources of influence on teachers' mathematics beliefs

What is missing from the literature is a research about the use of metaphoric and metonymic constructs to make sense of the abstract nature of mathematics. This paper fulfills this void by reporting the research of personal constructs of prospective teachers about mathematics and exploring the implications of the constructs on mathematics teaching, learning and assessment.

\section{THEORETICAL PERSPECTIVE}

Certain elements of Kelly's (1955) theory of personal construct (PCT) are useful as a guide to this research.

Kelly's (1995) personal construct theory has gained a wide acceptance in academic circles, particularly in the practice of clinical psychology. Today the theory of personal construct, or constructivist psychology as it is sometimes called, has become a burgeoning field of study culminating in the establishment of an academic journal called journal of constructivist psychology. According to Kelly (1995) personal construct theory has to do with a person's representation and interpretation of a phenomenon. That is, it is concerned with understanding individual interpretative scheme of phenomena in relation to how that individual perceives the phenomena as similar or dissimilar to those of others.

Kelly (1955) propounded that an individual differs from one another in his/her construct of an event. He stressed that "the chances are that, in the course of events each will get caught up in a different stream and hence be confronted with different navigational problem" (p. 55). Despite the differences in personal construct of events, Kelly states that "different persons can find common grounds which make their constructs equivalent" (p. 56). In other words, two or more people may have different experiences but they may share some common elements in their experiences such that it will be reasonable to say that they have similar experiences which lead them to construct events exactly the same way. However, it must be noted that a construct is not a rigidly permanent structure. For this reason Kelly (1995) stated that a person's construct of a bad phenomenon may change as a result of new experiences encountered, as the individual continues to construct and reconstruct the bad experience in relation to the new experience.

As a practicing clinician, Kelly used a flexible interview method to glean information from his clients and developed repertory grid methods as an analytical tool. He usually presented his clients with a series of three elements and asked them to discuss how two of the elements are similar and yet different. In this case, Kelly believed that a person is not a laboratory subject but a scientist who has his/her own way of seeing; who formulates theories (personal constructs), test them, and 
modifies them when necessary. As McQualter (1986) rightly puts it "the idea of personal construct system suggests the image of a person as an activist, constructing something" (p.5). McQualter (1986) went on to say that a personal construct is an individual stance that forms the anchor on which to develop his/her personality, attitudes, habits, concepts or philosophy.

\section{RESEARCH SETTINGS AND METHODOLOGY}

I approached a cohort of prospective teachers enrolled in the elementary stream in the bachelor of education program at an Ontarian university. I explained to them the objectives of the study, including their right to anonymity, confidentiality, withdrawal, and refusal to answer any questions deemed inappropriate during the interview. A total of 15 students expressed an interest to participate in the study and were asked to sign a consent form and to arrange the date and time with the researcher for interviews. Subsequently, five respondents withdrew on the grounds of the involved nature of the interviews, leaving ten participants. Of the ten respondents four were males and six females. All of them were enrolled in a one year, consecutive teacher preparation program, leading to the award of the bachelor of education degree. The mathematics background of the respondents varied: four of them had taken high school grade 12 general mathematics courses. In addition, only 2 of them had taken first year university statistics course. Finally, all the respondents were taking elementary mathematics methods courses as part of their teacher preparation requirements. Such courses aimed at introducing prospective teachers to provincial mandated mathematics curriculum, assessment approaches; strategies for teaching and learning mathematics as well as the use of concrete materials and technology.

\section{DATA COLLECTION METHODS AND ANALYSIS}

Two methods were used to collect data for the research: Mathematics autobiographies and semi-structured interviews. Mathematics autobiography is a personal narrative of one's mathematics learning experiences from k-university. It helps mathematics educators to understand student success stories, failures, struggles and motivation toward mathematics learning and application of mathematics outside of school setting. Most important of all, it provides mathematics educators useful information about how to help students to meet their learning needs and goals in their preparation as elementary school teachers.

\section{Autobiography}

I asked each respondent to write a two-page autobiography of his/her mathematics learning experiences from kindergarten to university level. The students were supposed to use the following questions as a guide:

1. What mathematics courses have you taken so far and when did you take them?

2. What have your experiences in mathematics classes been? Are they negative or positive? Why?

3. How do you feel toward mathematics teaching, learning or assessment?

4. What is your learning style/habit in relation to mathematics?

5. What do you understand by mathematics? What can you describe as mathematical?

6. Why should we learn or should not learn mathematics?

It happened that only three respondents had written their autobiographies in another course to assist the instructor to design appropriate pedagogies that would prepare them as effective elementary school teachers. So those three respondents 
handed their autobiographies to the researcher instead of writing new ones; while the other seven took two weeks to write their mathematics autobiographies.

\section{Semi-structured interview}

I interviewed each respondent by asking two sets of questions. The first set was based on their narratives in the autobiographies. The purpose was to seek clarification about their perceptions of the nature of mathematics, methods of effective teaching and learning of mathematics, its personal and societal importance, assessment and evaluation of mathematics learning. The second set of questions was more general, and they focused on how prospective teachers intended to teach mathematics given their conceptualizations. Each respondent was interviewed for approximately 35 minutes. All the interviews were audio-taped and transcribed by the researcher.

Follow up interviews helped the researcher not only to clarify themes and concepts in the respondents' narratives, but also to relate to the respondents the interview transcripts and to find out if they agreed to the recorded narratives. This process of respondent checking assisted the researcher to ensure validity of the narratives. Through the interviews I was able to gain a deeper insight into the respondents' mathematics autobiographies. First, the interviews added active voices to the narratives in the autobiographies; second, they helped to amplify themes and concepts in the mathematics autobiographies. Finally, the interviews provided the respondents another opportunity to add more than they wrote in their autobiographies and in some cases to reinterpret their narratives.

Both the mathematics autobiographies and interview transcripts were qualitatively analyzed using words and phrases contained in the respondents' narratives (Strauss and Corbin, 1990). The following elements of Kelly's (1995) theory of personal construct were used as guide for the data analysis: common grounds, similarities, and similar experiences. I read and analyzed each respondent's mathematics autobiography and interview transcript in order to identify common or similar themes or concepts running through them. The narratives in the transcripts were then grouped into categories of similar ideas, experiences, concepts, and themes in accordance with Kelly's (1955) theory of personal construct. Similar ideas, concepts, and themes were then grouped together to form clusters of related items and the researcher put them under common names he had created: metaphor, metonymy and a combination of metaphor and metonymy. During the analysis, I moved between the interview transcripts/ autobiographies and the literature in the field. This helped me to compare what experts in the field were saying in relation to the concepts or themes identified in the transcripts and autobiographies. This iterative process also helped me to pick quotes from the transcripts and autobiographies that related to category of themes and experts' assertions in the literature.

\section{FINDINGS AND DISCUSSION: STRATEGIES FOR CONCEPTUALIZING MATHEMATICS}

Common themes running through the mathematics autobiographies and the semi-structured interview transcripts were grouped into metaphor, metonymy, and a combination of the two, using Kelly's (1955) theory of personal construct as a guide. Under metaphoric conceptualization of mathematics, the following were the basic themes identified: structure of mathematics as a house or the way a house is constructed; ladder, hierarchy, and train subway system. Themes grouped under metonymy include mathematics as calculation, problem-solving, communication, reasoning, number and patterns, and cultural capital. 


\section{Metaphoric conceptions of mathematics}

Metaphoric conception of mathematics has to do with defining mathematics in terms of something else, such as climbing steps or ladder, symbols or building a house. Lakoff and Johnson (1980) stated that, metaphors are not only integral, indispensable part of our everyday language but also our thoughts and actions (Murphy, 2007). Lakoff and Johnson (1980) also went on to say that metaphors play an important role in helping us to make sense of our daily realities and circumstances in life. According to Lakoff and Johnson (1980), "the essence of metaphor is understanding and experiencing one kind of thing in terms of another "(p. 5). Similarly, Jeffery (1997) referred to metaphors as the use of "an image or other objects to depict specific phenomena in either similar or analogous terms" (p. 26). Sam (1999) also stated that "metaphors are something constructed by our minds that help us to present something in terms of something else"(p. 2). Metaphors are therefore a major way in which the prospective teachers established a relationship of similarity between two conceptual objects- nature of mathematics and mathematical objects.

One respondent, Marian, wrote the following metaphor of mathematics in her autobiography:

Mathematics is like a home. If you do not start with a solid foundation, if you omit essential materials, or if you construct it without love or care, then eventually the structure will collapse and disintegrate. Much like a home, if proper foundations in mathematics are not established and reinforced, then eventually we will not possess the principles, concepts and skills or tools necessary to be successful in further studies in it.

During the subsequent interview with Marian, she added the following comments to her conception of mathematics:

I find math to be very logical because you need one step to get to the next steps. And the following year you need those steps that you had learnt before in order to move on. You can't miss something in between...I like math because it is concrete, objective. There is always an absolute answer to every problem, but in the humanities things have a multiplicity of answers and are more divergent.

Another respondent, Merci, offered her conception of mathematics in her autobiography as follows:

Math is like a ladder to be climbed; you have to climb it step by step in order to reach the top successfully. As a math teacher, I need to be guided in a step by step process to reach an understanding of math concepts... I can recall many times when I asked my teachers to show me the steps again in order for me to have a better understanding. Sometimes I didn't get it and had to do it over and over again before I got it. Even now there are some math concepts that I still don't understand.

During an interview with Merci on her metaphoric conception of mathematics, she made the following narrative to defend her conception of mathematics:

It doesn't matter whether one is answering questions on percentage, proportion, long division, or fractions; there are definite procedures that one has to follow--- series of structured steps. If one forgets the procedures, one is stuck andcan not answer the questions. This is my experience of mathematics from kindergarten to university.

Similarly, Karen, a respondent, also agreed to both Marian's and Merci's conceptions of mathematics by offering the following:

I define mathematics as a system of skills and knowledge. But there are different skills for different sets of problems and some skills must be 
learnt first before others. For example, the skills to solve a long division problem is different from the one needed to find the area of geometric figures. In long division, for example, one has to understand multiplication first, and then subtraction second. These skills must be mastered carefully and practiced more often, so that we don't forget them.

Further, Linda also conceived mathematics as a subway train system where to get to one's destination, one has to pass through other stations. She believed that to get to station $\mathrm{C}$, one has to take the train from either station $\mathrm{A}$ or $\mathrm{B}$ and that it is impossible to get to station $\mathrm{C}$ without passing through the other stations. In terms of the theory of personal construct, Marian's, Merci's, Karen's and Linda's conceptions of the nature of mathematics are similar; though Marian uses the metaphoric language of building a house, Merci uses ladder, Karen uses hierarchy of skills, and Linda uses a subway train system. Their conceptions of mathematics are not different from that of the Cockcroft Committee report in 1992, a committee set up in Great Britain to study and report on the state of mathematics teaching and learning in that country. The committee states:

Mathematics is a hierarchical subject... The ability to proceed in this view is very often dependent on a sufficientunderstanding of one or more pieces of work which have gone before... Many pupils advance only a very shortdistance along the mathematical road during their years at school. Because of the hierarchical nature of mathematicsthese pupils do not reach a position from which they are able to tackle the more abstract branches of the subject with understanding or hope of success. (Ruthven, 1987, p. 244)

The conception of mathematics as hierarchical, structured, and ordered disciplined suggests that,for instance, a student cannot conceptualize and calculate percents without first understandingfractions or decimals. Nor can a student understand the concept of factoring in algebra without first understanding the multiplication of monomials, binomials and polynomials. This hierarchical notion of mathematics, according to Hewitt (1987) is problematic:

This image of mathematics learning that is endorsed by textbooks where later chapters rely on students remembering work from previous chapters. Many teachers also prepare their lessons based on what students have already done. This may all seem quite sensible, but it has many features which are problematic. First, there is an assumption that just because students have done a topic earlier, then later on those students will still feel confident and competent with that content. As any mathematics teacher will know student forget, and if students have forgotten the mathematics that the current lesson is built upon, then that means the students will have difficulties understanding the current topic as well. In fact, the building metaphor suitably demonstrates its own weakness. If one or two of the foundation blocks have become loose, or fallen down completely, then there is nothing which will hold up the building of any higher blocks. Suddenly there is no basis from which the higher content can be built. In such a situation, what is a teacher to do if their view of mathematics is based on the building block metaphor? (pp. 46-47)

Silver et al. (1990) have also critiqued the building metaphor of mathematics learning as narrowand distortion of realistic process of learning. They reject the theory that students learn little bylittle, from low to medium to high, and that they arrive in the mathematics classroom without anyknowledge of mathematics. To avoid climbing the ladder countless times, wreaking the foundation blocks of the 
house or failing to master the hierarchy of skills, Hewitt (1997) suggested that mathematics teachers should use mathematics root notions such as inverse, order, sameness, and difference which are parts of everyday vocabulary. In order words, using everyday vocabulary will help students to integrate mathematics concepts into their linguistic experiences. In addition, teaching students to understand the pattern of relationships between mathematics concepts such as decimal, fractions, percent, and proportion is an effective way to help them to grasp the whole conceptual picture rather than presenting each as a discrete concept.

\section{Metonymic conceptions of mathematics}

Metonymy, like metaphor, has also occupied the attention of cognitive linguists. This is mainlydue to its ubiquitous presence in language and thought (Lakoff and Johnson, 1980; Paradis, 2004; Nerlich, 2006). According to Radden and Kovecses (1999) metonymy is "a cognitive process inwhich one conceptual entity, the vehicle, provides mental access to another conceptual entity, thetarget, within the same idealized cognitive model" (p. 17). In the same way, Catalano and Waugh (2013) defined metonymy as "a stand for relationship in which something stands for something else it is related to or associated with "(p. 32). In the statement "mathematics is problem-solving", for instance, problem-solving is the vehicle that the communicator uses to assist the hearer to make sense of mathematics, the target entity. In this case, problem-solving is a pragmatic linguistic device that establishes a replacive relationship with mathematics. Problem-solving is then a conceptual entity that takes the place of mathematics and vice versa. Such replacive association between mathematics and problem-solving suggests that the mention of one implies the mention of the other.

To avoid any confusion, it is important to draw a clear line of demarcation between metonymy and metaphor. While metonymy is characterized with association between two conceptual entities, metaphor establishes a relationship of similarity between two conceptual entities. Nerlich (2006) has asserted that in "using metaphors speakers tell you more than they actually say; using metonyms they tell you more while saying less" (p. 111). This distinction implies that hearers should frame their clarification questions based on whether the statement is metonymic or metaphoric. To illustrate, when someone says that mathematics is a language it implies that language can substitute for mathematics. This is different from the statement that mathematics is like a language. In fact, the statement is comparing mathematics to language and in effect suggesting a resemblance between the two.

It should be noted that the distinction between metaphor and metonymy has not been wholly agreed by all linguists. Though some cognitive linguists regard metonymy as a subtype of metaphor (Genette, 1980; Searle, 1979), others treat each as a different category (Barcelona, 2011; Kovecses, 2006; Song, 2011). In this paper, the distinction between the two figures of speech is maintained based on the logic that metonymy is used for inference purposes where as metaphor is for analogy or comparison purposes (Fass, 1991).

With regard to metonymic conception of mathematics, prospective teachers defined mathematics by reducing it to some elements or components of mathematics, such as calculation, problem-solving, understanding, operations, equation, reasoning, communication, shapes, numbers or patterns. Sam's, Jon's, Kate's and Tom's conceptions of the nature of mathematics may be classified as metonymic. Sam had the following to say during the interview:

Mathematics should not be simply about memorizing number operations and formulas, especially if some of the students such as me have problems memorizing. On the contrary, mathematics should 
emphasize teamwork, reasoning, problem-solving and communication of shapes, numbers and patterns.

In a similar way, Jon constructed his conception of mathematics in this way: Mathematics is about problem-solving and understanding of concepts, operations, theorems and formulas. I realized that mathematics is about understanding, not about memorization of formulas, theorems, concepts or algorithms. By understanding, I mean two basic things. First, the ability to conceptualize the meaning of something without necessarily memorizing it is the form of symbols, pictures, or words. Second, the ability to use the concepts learned to solve some problems.

Kate, on the other hand, conceived mathematics in the following way:

Mathematics is about learning how we deal with, manage or handle quantities in our culture. In mathematics students learn how we (society) calculate percentage, ratios, averages, and use them, how we add money values, how we divide, multiply and subtract quantities. Once students have acquired this cultural capital, then they are more or less initiated into our culture. With this cultural capital they become smart consumers, producers, employees, and citizens.

Tom stated the following as his conceptualization of mathematics:

Mathematics is a reasoning activity... every aspect of mathematics involves reasoning and logic; whether it isabout counting, shapes, patterns, algebra, or sets. Many teachers of mathematics ignore this and teachmathematics as if it's some kind of magic, much to the peril of students. Students just copy, imitate, andsimply reproduce whatever they have been taught without understanding the underlying reasons or logic.

Reasoning, problem-solving, and quantitative management are integral aspects of school mathematics curriculum. However, according to Krulik and Rudnick (1982) what constitutes a problem depends on the mathematical development of the individual. They went on to define problem, exercise, and question. They posed the following question: what is $7 \times 6$ ? And they went on to say that when this is posed to future mathematics teachers it is merely a question, because it simply involves recall based on many years of experiences with multiplication. However, when the same question is asked of an elementary school student who is learning the concept of multiplication, then it is a drill or exercise.

Jon stressed the central importance of understanding in mathematics and defined understanding as the ability to grasp the meaning of mathematical concepts, theorems, principles and theories and use them to solve problems. Two comments may be relevant to Jon's conceptualization of mathematics. First, the yardstick for assessing understanding is not necessarily problem-solving. The ability to take knowledge and use it in any new ways is part of understanding; so is the ability to explain, generalize, or represent knowledge in other ways form part of understanding (Alagic and Emery, 2003). Thus understanding is made up of many things. Second, in mathematics learning both conceptual understanding and computational or procedural understanding are required in order to have a comprehensive understanding of a concept (Nesher, 1986; Steinbring, 1989; Andrews and Hatch, 1999).

Finally, Jon and Sam stated that they were opposed to mathematics learning that involves memorizing. Yet memorizing is essentially an integral part of mathematics learning. Accordingly, Davis (1994) offers the following guidelines:

They cannot or need not commit into memory a comprehensive list of mathematical statements conveying thefacts. There would be too many, indeed the list could never be complete. They should, of course 
memorize basicnumber bonds and multiplication table. Such memorizing can be very effective and efficient but clearly it needsto be highly selective. It is pointless, unless the pupil already understands what she is now arranging in her mindfor instant access. Good teachers give considerable thought to the best time in the pupil development for such memorizing to be encouraged. (p. 10)

While Davis (1994) stresses the importance of selective memorizing, Sam and Jon stress only understanding as the capstone for effective mathematics learning. Certainly, since students cannot memorize or recall the myriad of mathematics formulas, procedures and algorithms, any mathematics instruction based solely on memorizing algorithms is likely to discourage many students (Quilter and Harper, 1988). Steen (1989) has stated that memorizing rules or rote memorizing in mathematics must be reduced considerably, because it is an ineffective way of learning. Therefore, selective memorizing in mathematics is a useful strategy from a pedagogical and epistemological point of view. Brown (1999) also asserts that deemphasizing rote memorization in mathematics teaching and learning focuses student attention on understanding the subject matter. It should be noted that none of these authors are suggesting that memorizing in the mathematics classroom is bad in itself.

Further, Kate's conception of mathematics as a cultural initiation of dealing with quantitative aspects of life suggests that students should learn mathematics as a life tool (Andrews and Hatch, 1999), allowing them to become 'participating' citizenry in a society. Indeed, Kate's narrative suggests mathematical empowerment of students, which means gaining mastery over the use and application of mathematics. Ernest (2002) described three types of empowerment in mathematics education: mathematical, epistemological and social. He referred to mathematical empowerment as having mastery over the language, skills and practice in using and applying mathematics; while he sees epistemological empowerment as the growth in confidence in using, applying, and validating mathematical ideas. He defines social empowerment as the ability to use mathematics to make one' life, work, and society better. Thus, while the acquisition of mathematical knowledge and skills as a cultural capital will make one smart consumer, producer or citizen, it will not necessarily empower one to become a critical consumer, producer, or citizen in society. In fact, the mere acquisition of that cultural capital is most likely to make one a conforming member of society rather than a critical consumer, producer or citizen, who uses mathematics as a quantitative tool to examine and critique society with a view to making it a better place to live (Ball et al. 2005; Stinson, 2004).

Many researchers and scholars support Tom's conceptualization of mathematics as reasoning.

For example, part of the NCTM (1989) standards for teaching and learning mathematics take mathematics as reasoning which demands that students build sound arguments, justify their answers and solution processes, and draw logical conclusions. More recently, mathematics has been regarded a form of reasoning, requiring sense-making, justifying judgments, inferences, and conclusions on the part of both the teacher and the learner (Nebesniak, 2012; The Alliance Education Organization, 2006). Mathematical Reasoning can be made with words, pictures or diagrams (Jamnik, 2001).

As well, Baig and Halai's (2006) research indicated that grade six students can be taught fractions algorithms with reasoning. Nevertheless, they caution that teaching mathematical rules with reasoning can only be accomplished if three conditions exist- all of which Wood (2001) had indirectly articulated. First, the teacher has to establish a classroom setting where students can argue, raise critical questions, and describe their thinking comfortably to both their teacher and peers. Regarding this condition, Wood (2001) stated that the difference between a traditional class and a 
reform-oriented class is found in the degree to which explanations and justifications are permitted and made part of the culture of mathematics learning. Second, teachers should choose or design mathematical activities that provide students opportunities to explain, argue, and communicate their understanding. Third, teacher questioning should promote reasoning. But Baig and Halai (2006) admitted that teachers could not substantiate the multiplication of fractions rule with reasoning. Their research finding seems to imply that teachers cannot teach every mathematical rule with reasoning and that certain rules must be simply learned without reasoning; and that much also depends on the age, grade level, and other characteristics of the students.

Earlier, Steen (1999) stated that a restrict adherence to reasoning is not often needed in the application of mathematics. She added that sometimes intuition, instinct, estimates, and computer simulation are all that is needed. She further stated that in the course of ordinary life in the home or workplace, people either apply known formulas or procedures to solve standard problems or solve problems using some strategies. And that hardly do people in their homes or at work engage in the rigorous reasoning characteristic of formal mathematical reasoning. It may be concluded that it is an effective teaching practice to offer reasons for formulas, rules or algorithms but the age, grade level, and other things about the students must be taken into consideration in framing the reasoning.

\section{Metaphoric and metonymic conceptions of mathematics}

Some of the research participants' narratives may be representative of both metaphor and metonym. For example, Carol, one of the respondents, described mathematics by combining metaphoric and metonymic elements. She used the word symbols and problem-solving which are metaphoric and metonymic respectfully. However, she used it to denote operations performed in mathematics. Mike, on the other hand, uses the metonymic word calculations and metaphoric word language which make his conception of mathematics both metonymic and metaphoric. Smith believes mathematics is about quantitative reasoning and structured-steps which make his conception a combination of metaphor and metonymy. Carol's narratives are worth reproducing here:

The use of invented symbols and rules to solve quantitative problems in life...Symbols are operation signs such as addition, multiplication, and subtraction, equal sign, inequality sign, and square root sign. This definition is not based on the mathematics I learned in school or Teacher College; it is based in my own experience with mathematics. You may be surprised to know that no teacher has ever defined mathematics to me in elementary, high school, or teachers college.

In a similar vein, Mike conceptualized mathematics in the following way: In my opinion, mathematics involves calculation with numbers such as addition, multiplication, division, andsubtraction and the regulations and procedures governing such operations. It also involves language. You have tounderstand the meanings of these operations in order to apply them correctly to solve problems in one's daily life or workplace.

While Smith conceived mathematics as;

quantitative operations such as addition, subtraction, multiplication, division, square root, and squaring, One cannot understand these operations without a firm understanding of the structured procedures that are customarily used to carry them out. The procedures are as important as the conceptual meanings of these operations... These operations form a well-designed system; for example, addition has 
subtraction as its inverse; multiplication's opposite is division; squaring has square root as its opposite...

The conceptualization of the nature of mathematics as a set of rules has been acknowledged bymany mathematics educators (Burns, 1994; Countryman, 1992; Merseth, 1993). Merseth (1993), for instance wrote:

Many individuals believe that mathematics is largely rule-oriented body of knowledge that is acquired throughthe memorization of discrete facts and algorithmic rules. For example, in a survey of eighth and 12th gradestudents, researchers found that $40 \%$ of the students at both levels agreed with the statement that mathematicsis a set of rules, while $50 \%$ of the eighth graders and $12 \%$ of 12 th graders stated that mathematics involvesmostly memorizing, lending further credence to this rule-bound conception of the field. (p. 2)

Further, by conceptualizing mathematics as the calculation of quantities both Mike and Smith have ignored the non-quantitative aspects of mathematics-the logical aspects (Bako', 2002). The tendency to calculate when calculation is not required is very much a problem for students learning elementary mathematics, which Padmanabhan (2000) has labeled brute force calculation. Even where calculation is required, one should be able to explain why this is the case and the kind of calculation needed. I find Mike's conception of mathematics as a language worth commenting on. Certainly to understand and do mathematics effectively, students have to understand the specialized language of mathematics which, like any other language, has its own vocabulary, grammar, and punctuation.

However, Ball et al. (2005) advised teachers of mathematics to pay a closer attention in the classroom to the differences between technical and everyday uses of the English language. They went on to assert that words like odd, right, rational, equivalent, similar, radical, and groups are used in everyday talk as well as in other ways in mathematics. And that making these differences in meaning clear is important to effective mathematics teaching. Tapson (2002) also adds that mathematics language used at the school level causes a great deal of confusion to students because of similarity of definitions between certain concepts, making it increasingly difficult to ascertain which concept or word applies to which thing. Tapson (2000) seems to suggest that mathematics pedagogy at the school level needs precision language in order to avoid unnecessary confusion.

Further, the prospective teachers' metonymic conception of mathematics as calculation of quantity suggests that calculations are absolute and objective. Nonetheless, Borba (1992) has indicated that phrases often use in the news media and others to describe the certainty of mathematics include the following: it was mathematically proved, the numbers express the truth, the numbers speak for themselves; the equations show/assure that" (p. 332). Borba (1992) also stated that the uncertainty of mathematics becomes so glaring when applied to solve practical problems such as voting system and predicting future prices of housing. Consequently, prospective teachers who conceive mathematics as calculation or operation with numbers have to be careful how this conception influences their instructional practices, so that they would not produce students who place an absolute reliance on calculations without reasons or justifications.

Furthermore, Carol's, Mike's and Smith's conceptions of mathematics in terms of calculations, operations with numbers and symbols seem narrow and contrary to current perspectives on the nature of mathematics. Such conceptions of mathematics reduce mathematics to nothing other than a book of recipe. By contrast, Devlin's (1994) conceptualization of mathematics as the science of patterns, goes beyond the study of numbers and their operations, procedures, or shapes unlike Mike's and Carol's conceptualizations. In fact, Devlin's (1994) conceptualization of mathematics has the following ramification: it informs students 
and teachers alike that they have to pay closer attention to patterns and relationships in the physical environment. As well, when one takes mathematics as a bundle of rules and procedures one is likely to ignore or pay little attention to the logical reasoning undergirding those rules and procedures (Jamison, 2000).

\section{CONCLUSION: IMPLICATIONS FOR TEACHING, LEARNING AND ASSESSMENT OF MATHEMATICS}

The main purpose of this research was to identify and discuss prospective teachers' conceptualizations of the nature of mathematics, and explore their implications for teaching and learning of mathematics. With the guide of Kelly's theory of personal construct, respondents' narratives were group into themes and categories, and then classified into metaphors and metonymies and combination of the two. The results have demonstrated that metaphors and metonyms are useful linguistic devices that assisted prospective teachers to make-sense of the abstract nature of mathematics and are most likely to employ them in teaching and learning mathematics concepts whenever they are deemed appropriate. In addition, they are most likely to encourage their students to utilize metaphors and metonymies as thinking and sense-making tools. The use of metaphors and metonyms would be extremely helpful linguistic devices for students to make meanings out of mathematics learning as a majority of students have an aversion for mathematics due to their inability to make sense out of it.

The prospective teachers' conceptualizations of the nature of mathematics in terms of metaphors and metonyms may have implications for the teaching and learning of mathematics. This conclusion is consistent with earlier research studies and scholarly work on teacher conceptions of mathematics. Notably, Thompson (1984) and Ernest (1989) have argued that a teacher's beliefs and attitudes about the nature of mathematics have considerable influences on how they teach mathematics and expect their students to learn it. Hersh (1986) put it more succinctly, "A person's understanding of the nature of mathematics predicates that person's view of how teaching should take place in the classroom" (p. 13). Leatham (2006) has indicated that some teachers believe, based on their previous mathematics experiences that, students have to learn mathematics in a sequential manner. For example, they believe that students have to master the rudiments of multiplication first before they can understand division. All these research studies and scholarly writings strongly point out that teachers' conceptualizations of the nature of mathematics are not mere statements in futility.

However, this pedagogical norm is a sensible conception in some cases as teachers make complex decisions in the social context of teaching (Leatham, 2006). Carol, one of the research participants, for example, during the interview expressed the belief that students could not learn to understand the conceptual meaning of fractions unless they understand division. Mike, the other research participant, also believed that addition operation must be learned first before subtraction operation, explaining the hierarchical learning of mathematics concepts. Though these pedagogical beliefs have no absolute empirical support, they may facilitate effective teaching and learning of mathematics for some students but not for all students. Nevertheless, the main problem with the hierarchical view of mathematics learning is where it is articulated as an absolute rule, that must be applied regardless of student characteristics or teaching circumstances.

Again, conceiving mathematics in the metaphoric language of building, hierarchy, ladder, and subway train system implies that all students learn in incremental ways. Certainly, some students may prefer that a mathematics concept be taught to them step-by step, a piece at a time. After they have mastered the concepts in that fashion, 
they are able to relate the parts to the whole. Consequently, the building, laddering or hierarchical metaphoric concept of mathematics learning and teaching may well fit the learning styles of some students but certainly not all students. Teachers always have to bring together their knowledge of the subject-content and that of the characteristics of students in deciding how they can effectively teach specific mathematics concepts (Feiman-Nemser, 2001; Ellis and Berry III, 2005).

However, Sam's conceptualization of mathematics as understanding rather than memorizing number facts, operations and formulas is coterminous with the vision of school mathematics recommended by the NCTM (2000).Yetkin (2003) also contended that students who use rote memorization for the learning of mathematics have the tendency to over-rely on procedures and formulas, ignoring the deeply conceptual and analytical aspects of mathematics. The author further stated that understanding of mathematics concepts, symbols and operations can be obtained by connecting them with other forms of representation such as physical objects, pictures, everyday language, experiences, and student informal knowledge. That said, following Davis' (1994) advice, one cannot take memorization completely out of mathematics learning because selective memorization of basic number bonds and the multiplication table facilitates effective mathematics learning.

In the same way, reducing mathematics to language, calculation, operations with numbers/symbols or quantitative management may lead to a narrow view of mathematics. This is because it ignores the logical and cultural aspects of mathematics. Teachers who conceptualize mathematics as operations, for example, are most likely to ask their students the following question in solving mathematics problems: "Which of the operations do you have to use?" rather than helping students to understand the problem and make a decision about how to solve it. As a matter of fact, it is the logical aspects of mathematics that are fundamental to the development of students as critical citizenry, who may be consumers, producers, employers, employees and politicians. In fact, most students after graduating from school hardly remember the mathematics algorithms, rules or procedures they learned in school mathematics. Thus, the logic, reasoning and communicative aspects of mathematics should receive a preponderant pedagogical emphasis in teaching and learning of mathematics. Perhaps this explains why the Ontario mathematics curriculums regard them as part of the core mathematics processes and pay an enormous attention to them for teaching and learning, and assessment.

As well, the research has indicated, though indirectly, the importance of language for conceiving and expressing personal constructs about mathematics. Linguistic devices such as metaphors and metonyms are extremely an important pedagogical tool that will allow teacher educators to gain valuable insights into the words, ideas, understandings, and thoughts that prospective teachers hold about the nature of mathematics Prospective teachers constantly use language as a sense-making and memory tool. As a result, a critical task for teacher educators is to use language as a resource in pedagogical planning, to assist prospective teachers to understand the probable consequences of their metaphoric and metonymic conceptualizations of mathematics for teaching and learning. Ample opportunities should be made available to prospective teachers to think, talk, present and write about their mathematics experiences, beliefs, and perceptions from school and from the larger society which they belong.

\section{REFERENCES}

Alagic, M. \& Emery, S. (2003). Differentiating instruction with marbles: Is this algebra or what? International Journal for Mathematics Teaching and Learning,(July,8th). Accessed Dec.20, 2007 from http://www.cimt.plymouth.ac.uk/journal/algicemery 
Andrews, P. And Hatch, G. (1999). A new look at secondary teachers' conceptions of mathematics and its teaching, British Educational Research Journal, 25(2), 203-223.

Baig, S. \& Halai, A. (2006). Learning mathematical rules with reasoning. Eurasia Journal of Mathematics, Science, and Technology Education, 2(2), 15-39.

Bako', M. (2002) Why we need to teach logic and how we can teach it. International Journal of Mathematics Teaching and Learning. Accessed April 20, 2005 from.http://www.cimt plymouth.ac.uk/journal/bakom

Ball, D. L. (1988). Unlearning to teach mathematics. For The Learning of Mathematics, 8(2), 40-46.

Ball, D. L. (1990). Breaking with experience in learning to teach mathematics: The role of a preservice methods course. For The Learning of Mathematics, 10(2), 10-16.

Ball, D. (1991). Research on teaching mathematics: Making subject-matter knowledge part of the equation. In J. Brophy (Ed.), Advances in research on teaching (Vol. 2, pp. 1-48) Greenwich, CN: JAI Press

Ball, D.L., Goffney, I. M. \& Bass, H. (2005). The role of mathematics instruction in building a socially just and diverse democracy. The Mathematics Educator, 15(1), 2-6.

Barcelona, A. (2011). Reviewing the properties and prototype structure of metonymy. In RékaBenczes,

Antonio Barcelona and Francisco José Ruiz de Mendoza Ibáňez, (eds). Defining Metonymy in Cognitive Linguistics: Towards a Consensus View (pp. 7-57). Amsterdam/Philadelphia: John Benjamins.

Brown, A. (1999). A mathematics teaching even that changed my belief. Philosophy of Mathematics Education Journal \# 12. Accessed Nov. 12, 2007 from http://www.people.ex.ac

Borba, M.C. (1992). Teaching mathematics: Challenging the sacred cow of mathematical certainty. The Learning House, 65(6), 332-333.

Burns, M. (1994). Arithmetic: The last holdout. Phi Delta Kappan, 75(6) 471-476.

Catalano, T. and Waugh, R.L (2013). The language of money: How verbal and visual metonymy shapes public opinion about financial events. International Journal of Language Studies, 7(2), 11-60.

Countryman, C. (1992). Writing to learn mathematics. Portsmouth, NH: Heinemann Educational Books Inc.

Davis, A. (1994). 'Constructivism'. In A. Davis and D. Pettit (Eds.).Developing Understanding in primary mathematics (pp.11-13). London: The Falmer Press.

Devlin, K. (1994). Mathematics: The science of patterns: The search for order in life, mind, and the universe. New York: Scientific American Library.

Dossey, J. (1992). The nature of mathematics: Its role and its influence. In D. A. Grouws (Ed.), Handbook of research on mathematics teaching and learning (pp. 39-48). New York: Macmillan.

Ellis, M. W. and Berry III, R. Q. (2005). The paradigm shift in mathematics education: Explanation and implications of reforming conceptions of mathematics teaching and learning. The Mathematics Educator, 15(1), 1-17.

Ernest, P. (1989). The knowledge, beliefs, and attitudes of the mathematics teacher: A model. Journal of Education for Teaching, 15, 13-33.

Ernest, P. (1996).The nature of mathematics and teaching. Philosophy of Mathematics Education Newsletter, 9, November

Ernest, P. (2002). Empowerment in mathematics education. Philosophy of Mathematics Education Journal, \# $15 . \quad$ Accessed Nov. 2007 from http://www.people.ex.ac.uk/PErnest/pome15

Ernest, P. (2010). Mathematics and metaphor: A response to Elizabeth Mowat \& Brent Davis . Complicity: An International Journal of Complexity and Education, 7(1), 98-104

Fass, D. (1991). Met: A method for discriminating metonymy and metaphor by computer. Computational Linguistics, 17(1), 49-90.

Feiman-Nemser, S. (2001). From preparation to practice: Designing a continuum to strengthen and sustain teaching. Teacher College Record, 103, 1013-1055.

Gates, P. (2006). Going Beyond Belief Systems: Exploring a Model for the Social Influence on Mathematics Teacher Beliefs. Educational Studies in Mathematics 63(3). 347-369

Goulding, M., Rowland, T. \& Barber, P. (2002). Does it matter? Primary trainees' subject knowledge in mathematics. British Educational Research Journal, 28(5), 689-704. 
Hersh, R. (1986). Some proposals for revising the philosophy of mathematics. In T. Tymoczko(Ed.), New Directions in the philosophy of mathematics. Boston: Birkhauser.

Hewitt, D. (1987) Mixed ability mathematics: Losing the building block metaphor. Forum 1, 39(2), 46-49.

Jamnik, M. (2001). Mathematical reasoning with diagrams. Sanford, U.S.A: CSLI Press.

Jeffery, B. (1997). Metaphors and representation: Problems and heuristic possibilities in ethnography and social science writing. International Education, 27(1), 26-28.

Kelly,G. A. (1995). The psychology of personal constructs. New York: W.W. Norton\& Comp . Inc.

Kovecses, Z, (2006). Language, mind, and culture. Oxford: Oxford University Press

Krulik, S. \& Rudnick, J. A. (1982). Teaching problem solving too preservice teachers. Arithmetic Teacher, 23(2), 42-47.

Lakoff, G. \& Johnson, M. (1980). Metaphors we live by. Chicago: The University of Chicago Press.

Leatham, K. R. (2006). Viewing teachers' beliefs as sensible systems. Journal of Mathematics Teacher Education, 9, 91-102.

Lehrer, R. \& Franke, M. L(1992). Applying personal construct psychology to the study of teachers' knowledge of fractions. Journal for Research in Mathematics Education, 23(3), 223-241

McQualter, J.W. (1986). Becoming a mathematics teacher: The use of personal construct theory Educational Studies in Mathematics, 17, 1-14

Merseth, K. (1993). How old is the shepherd? An essay about mathematics education. Phi Delta Kappan, 74(7), 548-554.

Murphy, C. (2007). The constructive role of conceptual metaphor in children arithmetic: A comparison and contrast of Piagetian and embodied learning perspectives. Philosophy of Mathematics Education Journal, Nov., 22.

National Council of Teachers of Mathematics.(2000). Principles and standards for school mathematics. Reston, VA: National Council of Teachers of Mathematics.

Nebesniak, A. L (2012). Learning to teach mathematics with reasoning and sense-making. Unpublished doctoral dissertation. Lincoln, Nebraska: University of Nebraska.

Nerlich, B. (2006). Metonymy. Encyclopedia of Language and Linguistics, 109-113

Nesher, P. (1986) Are mathematical understanding and algorithmic performance related? For The Learning of Mathematics, 3, 7-11.

New Zealand Ministry of Education (1992). Mathematics in the New Zealand curriculum. Wellington: N.Z: Author.

Noyes, A. (2006). Using metaphor in mathematics teacher preparation. Teaching and Teacher Education, 22, 898-909

Ontario Ministry of Education (2005a) Mathematics: The Ontario curriculum grades 1-8. Toronto, Ontario: Author.

Ontario Ministry of Education (2005b). Mathematics: The Ontario curriculum grades 9-10. Toronto, Ontario: Author

Ontario Ministry of Education (2007) Mathematics: The Ontario curriculum grades 11-12. Toronto, Ontario: Author

Padmanabahan, R. (2000). Logical reasoning in mathematics vs. brute force calculations. Manitobamath Links, 1(1). Accessed December 12, 2005 from http://www.umanitoba.ca/Faculties/science/mathematics/new/issue1.pdf

Paradis, C. (2004). Where does metonymy stop? Senses, facets and active zones. Metaphors and Symbol, 19(4), 245-264

Presmeg, N. (2002). Beliefs about the nature of mathematics in the bridging of everyday and school mathematical practices. In G. Leder, E. Pehkonen, \& G. Torner (Eds.), Beliefs: A hidden variable in mathematics education? (pp. 293-312). Dordrecht: Kluwer

Quilter, D. \& Harper, E. (1988). Why we didn't like mathematics and why we can't do it. Educational Research, 30(2), 121-128.

Radden, G. \& Kovecses, Z. (1999). Towards a theory of metonymy. In Panther-U \& Radden, G. (eds). Metonymy in language and thought (pp.17-60). Amsterdam/Philadelphia: John Benjamins.

Ruthven, K. (1987).Ability stereotyping in mathematics. Educational Studies in Mathematics, $18,243-253$ 
Sam, C.L. (1999). Using metaphor analysis to explore adults' images of mathematics. Philosophy of Mathematics Education Journal, 12. Accessed December 2,2007 from http://www.people.ex.ac.uk/PErnest/pome12/article9.htm

Silver, E.A, Kilpatrick, J, \& Schlesinger, B. (1990). Thinking through mathematics. New York: College Entrance Examination Board.

Searle, J. (1979). Metaphor. In A Ortony (Ed.) metaphor and thought (pp.92-123). Cambridge: Cambridge University Press.

Song, S, (2011). Metaphors and metonymy- A tentative research into modern cognitive linguistics. Theory and Practice in Language Studies, 1(1), 68-73

Steel, D. and Widman, T. F. (1997). Practitioner's research: A study in changing perspective teachers' conceptions about mathematics and mathematics teaching and learning. School Science and Mathematics, 97(3), 192-199.

Steen, L.A.(1989). Teaching mathematics for tomorrow world. Educational Leadership, 47(1), 18-22

Steen, L. A. (1999). Twenty questions about mathematical reasoning. .L Stiff (ed.) in Developing mathematical reasoning in grades $k-12$ (pp.270-285), Reston, VA: National Council of Teachers of Mathematics.

Steinbring, H. (1989) Routine and meaning in mathematics classroom. For the Learning of Mathematics, 9(1), 24-33.

Stinson, D.W. (2004). Mathematics as "gate-keeper"(?): Three theoretical perspectives that ai towardempowering all children with the key to the gate. The Mathematics Educator, 14(1), 8-18.

Strauss, A.L, \& Corbin, J. (1990). Basics of qualitative research: Grounded theory procedures and techniques. Newbury Park, CA: Sage.

Tapson, F. (2002). The language of mathematics. International Journal of Mathematics Teaching and Learning. Accessed November 25, 2009 frohttp://www.plymouth.ac.uk/journal/ftlag

The Alliance education Organization (2006). Closing the achievement gap: But practices in teaching mathematics. Charleston, West Virgin: Author. Accessed Dec.20, 2007 from http:///www.educationalliance.org

Thompson, A. G. (1984). The relationship of teachers' conceptions of mathematics and mathematics teaching to instructional practice. Educational Studies in Mathematics, $15(2), 105-127$.

Timmerman, M. A. (2004). The influence of three interventions on perspective elementary teachers' beliefs about the knowledge base needed for teaching mathematics. School Science and Mathematics, 104(8), 369-382.

Wood, T. (2001). Teaching differently: Creating opportunities for learning mathematics. Theory into Practice(Spring), 40(2), 110-117.

Yetkin, E. (2003). Student difficulties in learning elementary mathematics. ERIC Clearinghouse for Science, Mathematics and Environmental Education, Reproduction No ED482727.

Zazkis, R. \& Campbell, S. (1996). Prime composition: Understanding uniqueness. The Journal of Mathematics Behavior, 15(2), 207-218.

Zazkis, R. \& Gunn, C. (1997). Sets, subsets and the empty set: Student constructions and mathematics conventions. Journal of Computers in Mathematics and Science, 16(1), 133169.

Zazkis, R. (1999). Challenging basic assumptions: Mathematical experience for preservice teachers. Journal of Mathematical Education in Science and Technology, 30(5), 631-650.

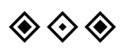

